\title{
Valorization of Kiwi by-Products for the Recovery of Bioactive Compounds: Circular Economy Model ${ }^{+}$
}

\author{
Franklin Chamorro ${ }^{1}$, María Carpena ${ }^{1,2}$, Bernabé Nuñez-Estevez ${ }^{1,2}$, Miguel A. Prieto ${ }^{1,2, *}$ and Jesus Simal-Gandara ${ }^{1, *}$ \\ 1 Nutrition and Bromatology Group, Faculty of Food Science and Technology, University of Vigo, \\ Ourense Campus, 32004 Ourense, Spain; chamorro1984@gmail.com (F.C.); \\ maria.carpena.rodriguez@uvigo.es(M.C.); bernabenunez16@gmail.com (B.N.-E.) \\ 2 Centro de Investigação de Montanha (CIMO), Instituto Politécnico de Bragança, \\ Campus de Santa 10 Apolonia, 5300-253 Bragança, Portugal \\ * Correspondence: mprieto@uvigo.es (M.A.P.); jsimal@uvigo.es (J.S.-G.) \\ + Presented at the 1st International Electronic Conference on Food Science and Functional Foods, 10-25 \\ November 2020; Available online: https://foods_2020.sciforum.net/.
}

Citation: Chamorro, F.; Carpena, M.; Nuñez-Estevez, B.; Prieto, M.A.; Simal-Gandara, J. Valorization of Kiwi by-Products for the Recovery of Bioactive Compounds: Circular Economy Model. Proceedings 2021, 70, 9. https://doi.org/10.3390/ foods_2020-07647

Published: 9 November 2020

Publisher's Note: MDPI stays neutral with regard to jurisdictional claims in published maps and institutional affiliations.

Copyright: $\odot 2020$ by the authors. Licensee MDPI, Basel, Switzerland. This article is an open access article distributed under the terms and conditions of the Creative Commons Attribution (CC BY) license (http://creativecommons.org/licenses /by/4.0/).

\begin{abstract}
Currently, agricultural production generates large amounts of organic waste, both from the maintenance of farms and crops, and from the industrialization of the product. Generally, these wastes are accumulated in landfills or burned, sometimes causing environmental problems. However, many scientific studies suggest that these residues are rich in bioactive compounds, so these matrices could be revalued for their use in food, cosmetic, or pharmaceutical industries. In this way, the circular and sustainable economy is favored, while obtaining products with high added value. In this case, this approach is applied to the residues generated from kiwi production, since numerous studies have shown the high content of kiwi in bioactive compounds of interest, such as phenolic compounds, vitamins, and carotenoids. These compounds have been reported for their antioxidant, anti-inflammatory, and antimicrobial activities, among other beneficial properties for health such as its use as prebiotic. Therefore, this article reviews the potential of residues derived from industrial processing and agricultural maintenance of kiwi as promising matrices for the development of new nutraceutical, cosmetic, or pharmacological products, obtaining, at the same time, economic returns and a reduction of the environmental impact of this industry, attaching it to the perspective of the circular economy.
\end{abstract}

Keywords: kiwi residues; circular economy; food applications; phenolic compounds; vitamins

\section{Introduction}

The kiwi is the best known fruit of the Actinidia genus (Actinidiaceae family), which has become a very popular product throughout the world due to its nutritional and organoleptic properties and its health benefits. It is native to China, and it is widely distributed, from regions with a tropical climate to areas with temperate-cold climates [1-3]. It comprises more than 70 species, of which three have great commercial interest: yellow (Actinidia chinensis), green (A. delicious), and resistant kiwi (A. arguta, also known as kiwiberry) $[4,5]$. This fruit is currently cultivated in several countries such as the United States, New Zealand, China, Japan, and Chile, and in European countries [6,7]. The latest data show that world kiwi production is around 4 million tons per year, with Asia in the lead and China standing as the region responsible for the half of world kiwi production [8,9].

In general, this fruit is consumed mostly raw; however, it is also used for the production of juices, wines, jams, and ice creams, among other products [2]. This industrialization produces wastes with biological capacities that could be of interest to the food, cosmetic, and pharmaceutical industries because they contain bioactive molecules with recognized health-promoting properties $[1,3,10]$. 
In a parallel context, in recent years, the interest of consumers for more natural and healthy products has led to the research and development of natural compounds with bioactive properties that can replace synthetic additives [11]. The use of fruit by-products is one of the global trends to address sustainability in food production [12]. In addition, the high awareness of society to adopt preventive health measures, such as a healthy and balanced diet and the use of food supplements with beneficial effects, has led to an increase in the demand for these new natural additives with bioactive capabilities such as having antioxidant, anti-inflammatory, or anti-cancer capabilities, as well as showing fewer side effects than synthetic ingredients [13].

\section{Associated Waste to Kiwi Production}

\subsection{Waste Derived from the Industrial Production of Kiwi Fruit}

The agricultural and food industries are responsible for generating millions of tons of by-products around the world [14]. As a consequence, the concepts of agriculture and circular economy usually appear together, because the residues derived from agricultural production can be used as a matrix to obtain compounds of interest [11]. Within the kiwi industry, the main residues are the skin, the seeds, and the pulp, in addition to the fruit that is not acceptable for commercialization or for processing due to strict quality and presentation standards. Regarding the skin, it has greater biological activity than the pulp $[6,15]$. Specifically, some authors claim that the skin is a good source of phenolic compounds (PCs) [16,17]. In the case of seeds, they are rich in unsaturated fatty acids, mainly linoleic acid $[18,1]$.

As regards the pulp bagasse, it is a rich source of various nutrients including vitamins, minerals, carbohydrates, some fatty acids, and carotenoids [18]. Its high content in vitamin $C$ stands out in addition to its high levels of vitamin $E$, fiber, potassium, and folic acid $[8,10]$, and the presence of pigments: carotenoids, chlorophylls, and anthocyanins $[7,19]$. The recovery of these fractions would be interesting in regards to their incorporation back into the commercial chain through new products [2,3], as exhibited in Figure 1.

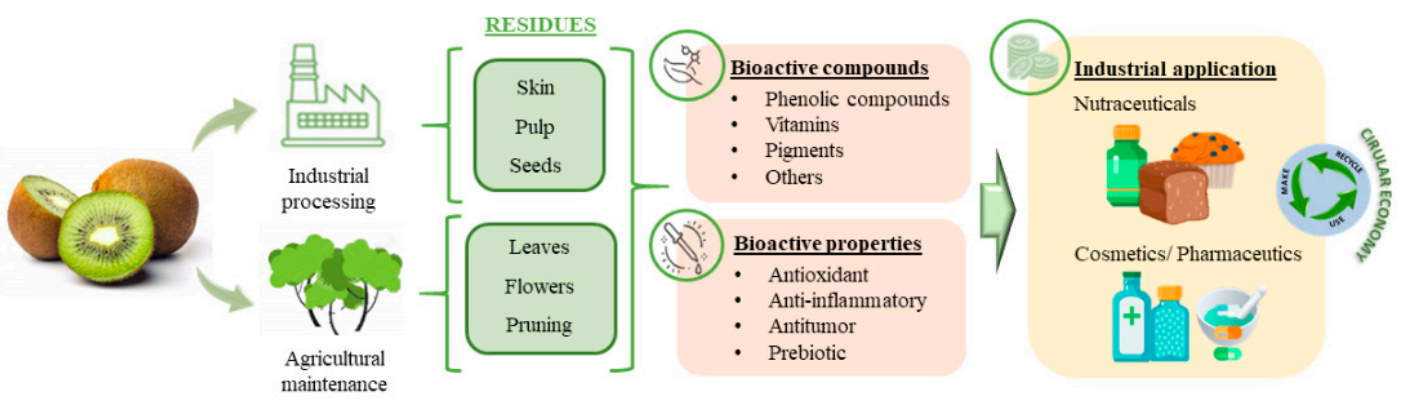

Figure 1. Global diagram of the circular economy of waste materials.

\subsection{Waste Derived from the Maintenance of Industrial Operations of the Kiwi Plant}

The exploitation of kiwi generates waste that is not usable and ends up incinerated or used as a substrate for the production of compost [3]. These residues include the leaves, stems, and, to a lesser extent, the flowers [14,19]. In general, they are rich in PCs, including neochlorogenic, chlorogenic, cryptochlorogenic, and caffeoylquinic acids, glycosylated quercetin and kaempferol derivatives, catechin, and type B procyanidin dimers [20].

The pruning process required in summer and winter gives rise to a significant mass of stems and leaves used as an extraction matrix. However, the woody stem of this plant complicates extraction processes due to the presence of lignin, which, on the other hand, is useful for the production of bioethanol $[19,21]$. The composition is similar to the leaves regarding PCs, with differences in pigment levels [22]. In respect of kiwi flowers, even though they are not categorized as a priori residue, in order to maintain optimum production, it is necessary to carry out maintenance tasks before and after flowering, called 
"clearing" [23]. Its richness and high concentration in volatile and PCs, coupled with the ease of their extraction, makes flowers an important source of PCs yet to be explored [24].

\section{Biological Activity}

Table 1 shows the different PCs described in kiwi fruit with free radical neutralization capabilities and, therefore, excellent antioxidant and anti-inflammatory properties $[1,25]$. Even so, the antioxidant capacity of kiwi has been proven in different studies, and it has been related to hydrophilic molecules, mainly vitamin C, followed by polyphenols [26]. For instance, the decoctions of kiwi pulp present antioxidant activity and capacity to capture reactive oxygen and nitrogen species [5].

Table 1. Phenolic compounds of Actinidia fruits.

\begin{tabular}{|c|c|c|c|c|c|c|c|}
\hline Composition & Chemical Structure & Res- & Ref. & Composition & $\begin{array}{l}\text { Chemical } \\
\text { Structure }\end{array}$ & Res- & Ref. \\
\hline \multirow{3}{*}{$\begin{array}{l}\text { Flavanols (derived } \\
\text { from quercetin and } \\
\text { kaempferol) }\end{array}$} & \multirow[b]{2}{*}{$\begin{array}{l}\text { Kaempferol-3-O-ga- } \\
\text { lactoside }\end{array}$} & $\mathrm{P}$ & [13] & Caffeoliquinic acid & & $\mathrm{P}$ & [25] \\
\hline & & $\mathrm{L}$ & {$[3,27]$} & $\begin{array}{l}\text { Di-O-caffeoylquinic } \\
\text { acid }\end{array}$ & & $\mathrm{P}$ & [25] \\
\hline & $\begin{array}{c}\text { Quercetin-3-O-ruti- } \\
\text { nóside }\end{array}$ & $\mathrm{P}$ & [13] & $\begin{array}{l}\text { Epigallocatechin gal- } \\
\text { late }\end{array}$ & & $\mathrm{P}$ & {$[25]$} \\
\hline \multirow{6}{*}{ Other flavanols } & \multirow{2}{*}{ Epicatechin } & Sk & [16] & Procatechuic acid & & Se & {$[28]$} \\
\hline & & $\mathrm{L}$ & {$[3,27]$} & \multirow{2}{*}{ P-coumaric acid } & & Se & {$[28]$} \\
\hline & \multirow{3}{*}{ Catechin } & Sk & [29] & & & $\mathrm{L}$ & {$[3,27]$} \\
\hline & & $\mathrm{L}$ & {$[3,27]$} & Ferulic acid & & Se & {$[28]$} \\
\hline & & B & {$[3,1,30]$} & \multirow{5}{*}{ Tocopherols } & $\alpha$-tocopherol & Sk & [16] \\
\hline & Quercetin & Sk & {$[16]$} & & $\beta$-tocopherol & Sk & {$[16]$} \\
\hline \multirow{2}{*}{ Flavan-3-ols } & $\begin{array}{l}\text { Polymeric procya- } \\
\text { nidins }\end{array}$ & $\mathrm{P}$ & [13] & & $\gamma$-tocopherol & Sk & [16] \\
\hline & $\begin{array}{c}\text { Procyanidin dimer } \\
\text { type B }\end{array}$ & $\mathrm{L}$ & {$[3,27]$} & & & Se & {$[28]$} \\
\hline \multirow{5}{*}{ Phenolic acids } & \multirow{2}{*}{ Caffeic acid } & $\mathrm{P}$ & [13] & & g-tocotrienol & Se & {$[18]$} \\
\hline & & Se & [28] & \multirow{3}{*}{ Organic acids } & Malic acid & Sk & {$[16]$} \\
\hline & \multirow{2}{*}{ Chlorogenic acid } & $\mathrm{P}$ & [13] & & Citric acid & Sk & [16] \\
\hline & & $\mathrm{L}$ & {$[3,27]$} & & Ascorbic acid & Sk & [16] \\
\hline & Quinic acid & $\mathrm{P}, \mathrm{Sk}$ & {$[13,16]$} & & & & \\
\hline Anthocyanins & $\begin{array}{l}\text { Cyanidin-3-O-sam- } \\
\text { bubioside }\end{array}$ & $\mathrm{P}$ & {$[13]$} & Fatty acids & Linoleic acid & Se & {$[28]$} \\
\hline
\end{tabular}

Res.: residues, P: pulp, L: leaves, Sk: skin, f: Flowers, Se: seeds, B: branches.

The anti-inflammatory activity has also been tested in in vivo and in vitro models [18]. At a cellular level, polyphenols (mainly certain phenolic acids) that are found in the seed oil decreased the secretion of pro-inflammatory cytokines IL- $1 \beta$ and TNF- $\alpha$ in RAW 264.7 cells induced by lipopolysaccharides (LPS) [28].

Kiwi extracts have been used to treat intestinal diseases such as constipation [31]. This function is attributed to the content of dietary fiber, mainly cellulose, pectin polysaccharides, and hemicelluloses, as well as the presence of glucuronoxylans and xyloglycans and the action of actinidin [10,32]. The presence of fiber could prevent the colonization of pathogenic bacteria and generate favorable changes in the intestinal microbiota, improving systemic health $[10,33]$.

It is important to highlight the antitumor activity of the different kiwi compounds, highlighting the water-soluble and thermolabile PCs. In this way, kiwi can be considered as an antitumor agent, acting in two different ways. On the one hand, it can contribute to 
the protection or reduction of DNA damage and mutagenesis processes, constituting a chemoprevention strategy [34] and, on the other hand, the prebiotic effect that has been above referred to could also contribute to the modulation of colon bacteria, contributing to the reduction of mutagens production [33].

Finally, kiwi extracts (skin, pulp, seeds, and stems) have shown bactericidal capacity against Staphylococcus aureus, Streptococcus pyogenes, Enterococcus faecalis, Salmonella typhi, Proteus mirabilis, Pseudomonas aeruginosa, Escherichia coli, and K. pneumoniae, among others [18].

\section{Sustainable Valorization}

Due to the phytochemical profile and biological properties of kiwi, it can be considered as a food with great potential for valorization, promoting new applications in the food, cosmetic, nutraceutical, and pharmaceutical industries [3,18,20,22]. To begin with, citric acid can be extracted from kiwi juice, being used in the food and pharmaceutical industry as an acidifying agent and flavor enhancer [35]. As regards natural antioxidants, PCs (obtained from the skin of kiwi) can be used in specific concentrations as an alternative to synthetic antioxidants [36]. Additionally, several articles have indicated that the injection of a kiwi-based solution (actinidin rich) confers tenderness benefits to the meat, which may be due to modifications in the myofibrillar components [37]. Another potential additive that can be extracted, in this case, from the kiwi skin, are pectins, which can be used for commercial purposes thanks to their thickening, texturizing, stabilizing, and gelling capacities [38]. Alternatively, PCs of kiwi can be used in nutraceutical formulations or to fortify foods or beverages, mainly for its effects as a prebiotic due to its beneficial effects on digestive health [6,35].

The potential for kiwi waste is much broader. For example, PCs have been investigated for their use as antioxidants in novel application forms, such as active packaging [36]. On the other hand, proanthocyanidins from kiwi skin have been used as insecticides, food preservatives, and cosmetic additives, given their ability to inhibit tyrosinase activity [39]. Finally, the use of kiwi pruning has also been suggested as an energy source with values similar to those of other forest resources [40].

\section{Conclusions}

This review aims to highlight the possibility of revaluing the residues from the industrial production and agricultural maintenance of kiwi fruit. The chemical components of kiwi show a variety with beneficial health effects, so kiwi could be considered a natural source of ingredients to develop functional products with applications such as additives or colorants, among other things. In this sense, residues from the cultivation and processing of kiwi could be revalued and transformed into new products, favoring the model of a circular economy that contributes to the reduction of the biological and environmental impact of the industrial and economic exploitation of this fruit.

Author Contributions: Conceptualization, methodology, resources, writing-original draft preparation, writing - review and editing, visualization, supervision, project administration, and funding acquisition: F.C., M.C., B.N.-E., M.A.P., and J.S.-G. All authors have read and agreed to the published version of the manuscript.

Funding: This research received no external funding.

Institutional Review Board Statement: Not applicable.

Informed Consent Statement: Not applicable.

Data Availability Statement: No new data were created or analyzed in this study. Data sharing is not applicable to this article.

Acknowledgments: The research leading to these results was funded by FEDER under the program Interreg V Spain-Portugal by POPTEC, IBERPHENOL Project (ref. 0377-Iberphenol-6-E) and by 
MICINN, supporting the Ramón \& Cajal grant for M.A. Prieto (RYC-2017-22891); by EcoChestnut Project (Erasmus+ KA202), supporting the work of M. Carpena; by Ibero-American Program on Science and Technology (CYTED-AQUA-CIBUS, P317RT0003); by UP4HEALTH Project (H2020-BBIJTI-2019); by Axudas Conecta Peme (Xunta de Galicia), supporting the IN852A 2018/58 NeuroFood Project, and by AlgaMar (www.algamar.com (accessed on 31 August 2020)).

Conflicts of Interest: The authors declare no conflict of interest.

\section{References}

1. Latocha, P. The Nutritional and Health Benefits of Kiwiberry (Actinidia arguta)-A Review. Plant Foods Hum. Nutr. 2017, 72, 325-334, doi:10.1007/s11130-017-0637-y.

2. Nishiyama, I.; Yamashita, Y.; Yamanaka, M.; Shimohashi, A.; Fukuda, T.; Oota, T. Varietal Difference in Vitamin C Content in the Fruit of Kiwifruit and Other Actinidia Species. J. Agric. Food Chem. 2004, 52, 5472-5475, doi:10.1021/jf049398z.

3. Pinto, D.; Delerue-matos, C.; Rodrigues, F. Bioactivity, phytochemical profile and pro-healthy properties of Actinidia arguta: A review. Food Res. Int. 2020, 136, 109449, doi:10.1016/j.foodres.2020.109449.

4. Giangrieco, I.; Proietti, S.; Moscatello, S.; Tuppo, L.; Battistelli, A.; La Cara, F.; Tamburrini, M.; Famiani, F.; Ciardiello, M.A.; Agro-ambientale, B.; et al. In fluence of Geographical Location of Orchards on Green Kiwifruit Bioactive Components. J. Agric. Food Chem. 2016, 64, 9172-9179, doi:10.1021/acs.jafc.6b03930.

5. Margarida, A.; Pinto, D.; Fernandes, I.; Gonçalves, T.; Costa, H.S.; Freitas, V.; Rodrigues, F.; Oliveira, M.B.P.P. Infusions and decoctions of dehydrated fruits of Actinidia arguta and Actinidia deliciosa : Bioactivity, radical scavenging activity and e ff ects on cells viability. Food Chem. 2019, 289, 625-634, doi:10.1016/j.foodchem.2019.03.105.

6. Latocha, P.; Łata, B.; Stasiak, A. Phenolics, ascorbate and the antioxidant potential of kiwiberry vs. common kiwifruit : The effect of cultivar and tissue type. J. Funct. Foods 2015, 19, 155-163, doi:10.1016/j.jff.2015.09.024.

7. Nishiyama, I. Fruits of the Actinidia Genus. Adv. Food Nutr. Res. 2007, 52, 293-324, doi:10.1016/S1043-4526(06)52006-6.

8. Pérez-Burillo, S.; Oliveras, M.J.; Quesada, J.; Rufián-Henares, J.A.; Pastoriza, S. Relationship between composition and bioactivity of persimmon and kiwifruit. Food Res. Int. 2018, 105, 461-472, doi:10.1016/j.foodres.2017.11.022.

9. FAOSTAT Statistical Database Food and Agriculture Organization of the United Nations. Available online: http://www.fao.org/faostat/en/\#data/QC (accessed on 31 August 2020).

10. Richardson, D.P.; Ansell, J.; Drummond, L.N. The nutritional and health attributes of kiwifruit: A review. Eur. J. Nutr. 2018, 57, 2659-2676, doi:10.1007/s00394-018-1627-z.

11. Jimenez-Lopez, C.; Fraga-Corral, M.; Carpena, M.; García-Oliveira, P.; Echave, J.; Pereira, A.G.; Lourenço-Lopes, C.; Prieto, M.A.; Simal-Gandara, J. Agriculture waste valorisation as a source of antioxidant phenolic compounds within a circular and sustainable bioeconomy. Food Funct. 2020, doi:10.1039/d0fo00937g.

12. Kheirkhah, H.; Baroutian, S.; Young, S. Food and Bioproducts Processing Evaluation of bioactive compounds extracted from Hayward kiwifruit pomace by subcritical water extraction. Food Bioprod. Process. 2019, 115, 143-153, doi:10.1016/j.fbp.2019.03.007.

13. Wojdyło, A.; Nowicka, P.; Oszmian, J. Phytochemical compounds and biological effects of Actinidia fruits. J. Funct. Foods 2017, 30, 194-202, doi:10.1016/j.jff.2017.01.018.

14. Bandara, N.; Chalamaiah, M. Bioactives from agricultural processing by-products. Encycl. Food Chem. 2018, 472-480, doi:10.1016/B978-0-08-100596-5.22408-6.

15. Skinner, S.J.M.; Hunter, D.; Cho, S.; Skinner, M. The Potential Health Benefits of the Subtropical Fruits Kiwifruit, Feijoa and Tamarillo. In Bioactives in Fruit: Health Benefits and Functional Foods; John Wiley \& Sons, Ltd.: Hoboken, NJ, USA, 2013; pp. 169195, doi:10.1002/9781118635551.ch8.

16. Dias, M.; Caleja, C.; Pereira, C.; Calhelha, R.C.; Kostic, M.; Sokovic, M.; Tavares, D.; José, I.; Barros, L.; Ferreira, I.C.F.R. Chemical composition and bioactive properties of byproducts from two di ff erent kiwi varieties. Food Res. Int. 2020, 127, 108753, doi:10.1016/j.foodres.2019.108753.

17. Yang, H.; Lee, Y.; Han, K.; Singh, H.; Yoon, M.; Park, J.; Cho, C.; Cho, S. Green and gold kiwifruit peel ethanol extracts potentiate pentobarbital-induced sleep in mice via a GABAergic mechanism. Food Chem. 2013, 136, 160-163, doi:10.1016/j.foodchem.2012.07.111.

18. He, X.; Fang, J.; Chen, X.; Zhao, Z.; Li, Y.; Meng, Y.; Huang, L. Actinidia chinensis Planch: A Review of Chemistry and Pharmacology. Front Pharmacol. 2019, 10, 1-18, doi:10.3389/fphar.2019.01236.

19. Picchi, G.; Lombardini, C.; Pari, L.; Spinelli, R. Physical and chemical characteristics of renewable fuel obtained from pruning residues. J. Clean. Prod. 2018, 171, 457-463, doi:10.1016/j.jclepro.2017.10.025.

20. Almeida, D.; Pinto, D.; Santos, J.; Vinha, A.F.; Palmeira, J.; Ferreira, H.N.; Rodrigues, F.; Oliveira, M.B.P.P. Hardy kiwifruit leaves (Actinidia arguta): An extraordinary source of value-added compounds for food industry. Food Chem. 2018, 259, 113-121, doi:10.1016/j.foodchem.2018.03.113.

21. Manzone, M.; Gioelli, F.; Balsari, P. Kiwi clear-cut: First evaluation of recovered biomass for energy production. Energies 2017, 10, 1837, doi:10.3390/en10111837. 
22. Marangi, F.; Pinto, D.; De Francisco, L.; Alves, R.C.; Puga, H.; Sut, S.; Dall, S.; Rodrigues, F.; Oliveira, M.B.P.P. Hardy kiwi leaves extracted by multi-frequency multimode modulated technology: A sustainable and promising by-product for industry. Food Res. Int. 2018, 112, 184-191, doi:10.1016/j.foodres.2018.06.029.

23. Salinero, C.; Sainz, M.J. EFA 40/05: Técnicas de cultivo de kiwi. Estac. Fitopatol. Areeiro 2005, 4, 4-5.

24. Trinh, L.T.P.; Choi, Y.S.; Bae, H.J. Production of phenolic compounds and biosugars from flower resources via several extraction processes. Ind. Crops Prod. 2018, 125, 261-268, doi:10.1016/j.indcrop.2018.09.008.

25. Leontowicz, H.; Leontowicz, M.; Latocha, P.; Jesion, I.; Park, Y.S.; Katrich, E.; Barasch, D.; Nemirovski, A.; Gorinstein, S. Bioactivity and nutritional properties of hardy kiwi fruit Actinidia arguta in comparison with Actinidia deliciosa "Hayward" and Actinidia eriantha "Bidan". Food Chem. 2016, 196, 281-291, doi:10.1016/j.foodchem.2015.08.127.

26. D’Evoli, L.; Moscatello, S.; Lucarini, M.; Aguzzi, A.; Gabrielli, P.; Proietti, S.; Battistelli, A.; Famiani, F.; Böhm, V.; LombardiBoccia, G. Nutritional traits and antioxidant capacity of kiwifruit (Actinidia deliciosa Planch., cv. Hayward) grown in Italy. J. Food Compos. Anal. 2015, 37, 25-29, doi:10.1016/j.jfca.2014.06.012.

27. Kleszczyn, H.; Cyboran, S.; Oszmian, J. Chemico-Biological Interactions Modification of the properties of biological membrane and its protection against oxidation by Actinidia arguta leaf extract. Chem. Biol. Interact. 2014, 222, 50-59, doi:10.1016/j.cbi.2014.08.012.

28. Deng, J.; Liu, Q.; Zhang, C.; Cao, W.; Fan, D.; Yang, H. Extraction optimization of polyphenols from waste kiwi fruit seeds (Actinidia chinensis Planch.) and evaluation of its antioxidant and anti-inflammatory properties. Molecules 2016, 21, 832, doi:10.3390/molecules21070832.

29. Alim, A.; Li, T.; Nisar, T.; Ren, D.; Zhai, X.; Pang, Y.; Yang, X. Antioxidant, antimicrobial, and antiproliferative activity-based comparative study of peel and flesh polyphenols from actinidia chinensis. Food Nutr. Res. 2019, 63, 1-10, doi:10.29219/fnr.v63.1577.

30. Lee, J.; Sowndhararajan, K.; Kim, M.; Kim, J.; Kim, D.; Kim, S.; Kim, G.; Kim, S.; Jhoo, J. Antioxidant, inhibition of a -glucosidase and suppression of nitric oxide production in LPS-induced murine macrophages by different fractions of Actinidia arguta stem. Saudi J. Biol. Sci. 2014, 21, 532-538, doi:10.1016/j.sjbs.2014.01.006.

31. Ansell, J.; Butts, C.A.; Paturi, G.; Eady, S.L.; Wallace, A.J.; Hedderley, D.; Gearry, R.B. Kiwifruit-derived supplements increase stool frequency in healthy adults: A randomized, double-blind, placebo-controlled study. Nutr. Res. 2015, 35, 401-408, doi:10.1016/j.nutres.2015.04.005.

32. Drzewiecki, J.; Latocha, P.; Leontowicz, H.; Leontowicz, M.; Park, Y.S.; Najman, K.; Weisz, M.; Ezra, A.; Gorinstein, S. Analytical Methods Applied to Characterization of Actinidia arguta, Actinidia deliciosa, and Actinidia eriantha Kiwi Fruit Cultivars. Food Anal. Methods 2016, 9, 1353-1366, doi:10.1007/s12161-015-0309-1.

33. Nishimura, M.; Okimasu, Y.; Miyake, N.; Tada, M.; Hida, R.; Negishi, T. Inhibitory effect of Actinidia arguta on mutagenesis, inflammation and two-stage mouse skin tumorigenesis. Genes Environ. 2016, 38, 25, doi:10.1186/s41021-016-0053-9.

34. Hunter, D.C.; Skinner, M.A.; Ferguson, A.R. Kiwifruit and health. In Fruits, Vegetables, and Herbs: Bioactive Foods in Health Promotion; Elsevier: Amsterdam, The Netherlands, 2016; pp. 239-269, ISBN 978012802989.

35. Cassano, A.; Donato, L.; Conidi, C.; Drioli, E. Recovery of bioactive compounds in kiwifruit juice by ultrafiltration. Innov. Food Sci. Emerg. Technol. 2008, 9, 556-562, doi:10.1016/j.ifset.2008.03.004.

36. Cunha, L.C.M.; Lúcia, M.; Monteiro, G.; Lorenzo, J.M.; Munekata, P.E.S.; Muchenje, V.; Allan, F.; De Carvalho, L.; Conte-junior, C.A. Natural antioxidants in processing and storage stability of sheep and goat meat products. Food Res. Int. 2018, 111, 379-390, doi:10.1016/j.foodres.2018.05.041.

37. Martin, H.; Cordiner, S.B.; Mcghie, T.K. Function Kiwifruit actinidin digests salivary amylase but not gastric lipase. Food Funct. 2017, 8, 3339-3345, doi:10.1039/c7fo00914c.

38. Güzel, M.; Akpınar, Ö. Food and Bioproducts Processing Valorisation of fruit by-products : Production characterization of pectins from fruit peels. Food Bioprod. Process. 2019, 115, 126-133, doi:10.1016/j.fbp.2019.03.009.

39. Chai, W.; Shi, Y.; Feng, H.; Xu, L.; Xiang, Z.; Gao, Y.; Chen, Q. Structure Characterization and Anti-tyrosinase Mechanism of Polymeric Proanthocyanidins Fractionated from Kiwifruit Pericarp. J. Agric. Food Chem. 2014, 62, 6382-6389, doi:10.1021/jf501009v.

40. Moreira, D.M.; Ferreira, V.; Resende, P.R.; Pinho, C. Determination of kinetic data through the fluidized bed combustion of chars made from vine and kiwi pruning wastes. Energy Rep. 2020, 6, 615-619, doi:10.1016/j.egyr.2019.09.035. 